\title{
Sustainability science must challenge common sense: a response to Bodin (2021)
}

\author{
Ellinor Isgren ${ }^{1}$ (i) . Stefano B. Longo ${ }^{2,3}$
}

Received: 30 August 2021 / Accepted: 31 January 2022 / Published online: 21 February 2022

(c) The Author(s) 2022

\begin{abstract}
In this comment, we respond to the claim of (Bodin, Sustain Sci 16: 2151-2155, 2021) that sustainability science, as a research community, has begun to "lean to the left" in a problematic manner. On one hand, we remain unconvinced by the examples cited as indications for this tendency, and argue for caution in making such judgements. On the other hand, we hold that that there may be reasons for seemingly "left leaning" positions which are scientific rather than purely political or ideological. Finally, we urge sustainability scientists to take heed of social theorists' insights regarding the pitfalls of common sense analysis. This can better enable open and reflexive debate on the field's development as well as the challenges it seeks to address.
\end{abstract}

Keywords Critical sustainability science $\cdot$ Science/policy interface $\cdot$ Transformation $\cdot$ Objectivity $\cdot$ Social analysis

\section{Introduction}

In "Has sustainability science turned left?", Bodin (2021) raises concerns that sustainability science is experiencing difficulties navigating the tensions between science and politics. Bodin is correct in highlighting the importance of maintaining scientific legitimacy, especially in politically polarized times. It is also hard to argue with the call to embrace "openness and critical debate", and the idea that as researchers we need to constantly confront our personal values and assumptions and be wary of how they shape our interpretations of the world. Such remarks are commonplace within sustainability science literature, and numerous principles and guidelines have been proposed to these ends.

Handled by Osamu Saito, Institute for Global Environmental Strategies, Japan.

Ellinor Isgren

ellinor.isgren@lucsus.lu.se

1 Lund University Centre for Sustainability Studies (LUCSUS), P.O. Box 170, 22100 Lund, Sweden

2 Department of Sociology and Anthropology, North Carolina State University, 10 Current Drive, Suite 334, Campus, Box 8107, Raleigh, NC 27695-8107, USA

3 Department of Sociology, Lund University, P.O. Box 114, 22100 Lund, Sweden
Other points, however, are in need of further discussion and - we argue-rethinking. We will limit our reply to two main points of discussion: (1) that sustainability science has indeed 'turned left', and (2) that, if this were to be true, this poses a problem for the legitimacy of the science. With the aim of moving the discussion forward, we suggest, finally, that the concerns stem in part from limited engagement with social theory, which can result in 'common-sense' social analysis. While we recognize that Bodin's (2021) Comment article is a brief foray aimed at stimulating debate, we believe that more attention to the concerns raised here will make for a more fruitful (and indeed "open and critical") conversation.

\section{Sustainability science and political ideologies}

On the first point, that sustainability science has turned left, what substantiation does Bodin (2021) provide? Since personal interactions at conferences and workshops are difficult to comment on, we focus on what the article more objectively offers as indications. One is that according to Google Scholar, recent years have seen a rapid increase in the number of publications using the term "environmental justice". But is this a good indication of political leanings within the field of sustainability science? The article for 
example mentions the concept of ecosystem services as a more 'right leaning' one. The amount of publications using this term has also grown dramatically in the same period (considerably more so, in fact, than environmental justice). Does this indicate that sustainability science has 'turned right'? Perhaps, but Google Scholar search hits are unlikely to tell us. First, it matters how concepts are employed by researchers, and second, sustainability science (while hard to define) cannot be equated with all of academia. Further, the growth of research institutions and structure of modern academia have driven new norms and institutional expectations in research production, causing an overall increase in total publications (Johnson et al. 2018). Thus, with any research topic, it takes careful analysis to assess whether an increase indicates anything at all beyond the massive increase in all published research articles over the last 30 years. Contrary to Bodin's perception that "sustainability science is leaning too much to the left", we have noted that many prominent strands of sustainability research may be characterized as leaning "right", or we would rather say, in an economically conservative direction. Bodin (2021) mentions an obvious example, the work around "Engaging private profit-maximizing corporations in instigating voluntarily change for sustainability". Less self-evidently, work that highlights individual lifestyle, "inner" dimensions or transdisciplinary co-production can similarly contribute to perpetuating existing structures unless this is consciously countered. ${ }^{1}$ This is a different discussion; our point is that the field's leanings are by no means unequivocal.

As further evidence, Bodin (2021) goes on to note the growing attention to power and inequity, and finally laments that the literature regularly criticizes "neoliberalism and capitalism" in an imprecise or unreflective manner. The latter undoubtedly exists in sustainability science and elsewhere. But here it would have been helpful to back up the claim with at least a few examples, as well as some exceptions (that is, 'good' critical analysis). We do not think the author wishes to suggest that critiques of neoliberalism and capitalism by default lack nuance, precision, reflexivity and objectivity, but unfortunately, that is not far from how the argument reads. The former, meanwhile, brings us to the second point of discussion: whether what the author interprets as signals of "left leaning" in sustainability science is in fact problematic.

This assessment ultimately rests on a view that sustainability researchers' attention to issues of inequality, injustice and power asymmetries is the result of personal ideology and political conviction, rather than sound analysis. This marks a more fundamental problem with the line of

\footnotetext{
${ }^{1}$ As recognized at times; e.g. Mont and Plepys (2008); Polk (2014); Wamsler et al. (2018).
}

reasoning presented in the article. It ignores or invalidates as "dogmatic" decades of scientific work within sustainability science (and related areas like political ecology and environmental sociology) which has shown - through nuanced and empirically substantiated analysis-ways in which systemic inequalities and power imbalances are often intricately intertwined with environmental problems and their drivers (e.g., Jerneck et al. 2011; Jorgenson 2015; Leach et al. 2018; see also InfluenceMap 2021). This may prompt recommendations that align with proposals predominantly associated with 'the left', but does this necessarily indicate that the analysis is politically motivated? We suggest that it does not, and that claims regarding abandonment of scientific methods or reflexivity must be based on careful analysis and interpretation.

As Bodin (2021) contends, research that points in the direction of major social transformation can sometimes be guilty of lacking specifics regarding the road forward. ${ }^{2}$ But we must remember that the more deeply structural a problem is understood to be, the more inherently difficult it is to propose 'practical' solutions. The historical, cultural, and ecological specificity of various concerns can furthermore make it necessary for social analysts to practice humility in regard to developing solutions, and recognize that specifics must be emergent in relation to the context and changing circumstances. It is also more difficult to investigate "cracks" in not-yet-existing alternatives-as Bodin (2021) suggeststhan in an existing paradigm. Are these reasons to give up on such projects, in favor of more "pragmatic" solutions like science-industry collaboration? Certainly not in cases where we have good reasons to think that this so-called pragmatism will not actually solve the problem, or even make it harder to solve (e.g., Leach et al. 2018). Instead, we need to intensify the efforts to identify, develop, evaluate and experiment with promising alternatives (Harnesk and Isgren 2021).

While there are clearly many ways in which sustainability science can become more effective at achieving its mission, the idea put forth by Bodin (2021) that progress is being hindered by "de-platforming", or denying access to conservative economists and the like, due to personal views and an inability to separate the "person from the argument," appears unjustified. It is hard to fruitfully parse out this part of the argument as it seems to confuse critical perspectives with dominant ideas, which are certainly not lacking a platform (Söderbaum 2013). But if dominant or mainstream ideas encounter more resistance within sustainability science than in society at large, there may be rational reasons for this. Sustainability science has embraced solutions-oriented approaches that often by necessity challenge

\footnotetext{
2 See for example Kallis et al. (2018) on degrowth and Edelman (2014) on food sovereignty.
} 
business-as-usual. Thus, proposed or implied social changes for sustainable development may bristle against the statusquo. Casting this divergence from the mainstream as rooted in dogmatism (as opposed to sensible pragmatism) risks doing exactly what Bodin (2021) suggests it seeks to avoid: silencing uncomfortable conversations about what sustainability means and requires.

\section{The necessity of social theory when asking social questions}

This leads us, finally, to an overarching concern with the article and with some sustainability science more broadly: the way social analysis is developed as if it is simply a common-sense endeavor. Antonio Gramsci (1971) analyzed the role of "common sense," or the generally held assumptions of a given society, in relation to political-economic matters. Common-sense notions about what is socially practical, reasonable, and even efficient abound within all social institutions, and scientific ones are not exempt (Marcuse 1991). Taking on social analysis-for example, of the relationship between political ideologies and sustainability science-without deep, nuanced, and theoretically informed understanding of social structures, institutions and forces, as if it is a straightforward exploration, is problematic. The formulations, definitions, and logical implications that may emerge as a result can unwittingly reproduce and reinforce existing - and in the current era, often unsustainable-conditions.

The so-called political leaning that Bodin (2021) identifies may not simply be attributed to ideology or the political preferences of analysts, but also to different training in social analysis and theory. Social analysts can draw on rich theoretical traditions that reveal the taken-for-granted (common sense) assumptions about sociohistorical conditions, social processes, and individual behaviors, which may prompt them to present analyses that challenge existing social circumstances (Longo et al. 2021). Gramsci (1971) and many others clarify that reflexive awareness of the position of the analyst in their social setting is indeed key to this development. Bodin (2021) rightly recognizes the need for reflexive analysis, but it is not clear that the article applies this in practice. We contend that greater attention to doing so would have made it much more difficult to reasonably conclude that sustainability science is leaning left in a manner that diminishes its scientific contributions.

Funding Open access funding provided by Lund University. SBL was supported by the Swedish Research Council, grant no. 2019-05766.

Open Access This article is licensed under a Creative Commons Attribution 4.0 International License, which permits use, sharing, adaptation, distribution and reproduction in any medium or format, as long as you give appropriate credit to the original author(s) and the source, provide a link to the Creative Commons licence, and indicate if changes were made. The images or other third party material in this article are included in the article's Creative Commons licence, unless indicated otherwise in a credit line to the material. If material is not included in the article's Creative Commons licence and your intended use is not permitted by statutory regulation or exceeds the permitted use, you will need to obtain permission directly from the copyright holder. To view a copy of this licence, visit http://creativecommons. org/licenses/by/4.0/.

\section{References}

Bodin Ö (2021) Has sustainability science turned left? Sustain Sci 16(6):2151-2155. https://doi.org/10.1007/s11625-021-01017-7

Edelman M (2014) Food sovereignty: forgotten genealogies and future regulatory challenges. J Peasant Stud 41(6):959-978

Gramsci A (1971) Selections from the prison notebooks of Antonio Gramsci: Ed. and Transl. by Quintin Hoare and Geoffrey Nowell Smith. International Publishers, New York

Harnesk D, Ellinor I (2021) Sustainability as a Real Utopia-heuristics for transformative sustainability research. Environ Plan E Nature Space. https://doi.org/10.1177/25148486211018570

InfluenceMap (2021) Industry associations and European climate ambition. How European industry lobbyists are misaligned with science-based pathways to net-zero emissions. London. https://influ encemap.org/report/Industry-Associations-and-European-Clima te-Ambition-fdaeeb57dc404c90aaf2f82bbd729733

Jerneck A et al (2011) Structuring sustainability science. Sustain Sci 6(1):69-82

Johnson R, Anthony W, Michael M (2018) The STM report. An overview of scientific and scholarly publishing. The Hague: STM: International Association of Scientific, Technical and Medical Publishers. https://www.stm-assoc.org/2018_10_04_STM_ Report_2018.pdf

Jorgenson AK (2015) Inequality and the carbon intensity of human well-being. J Environ Stud Sci 5(3):277-282

Kallis G et al (2018) Research on degrowth. Annu Rev Environ Resour 43(1):291-316

Leach $\mathrm{M}$ et al (2018) Equity and sustainability in the anthropocene: a social-ecological systems perspective on their intertwined futures. Global Sustain. https://doi.org/10.1017/sus.2018.12

Longo $S$ et al (2021) Sociology for sustainability science. Discover Sustain 2:47. https://doi.org/10.1007/s43621-021-00056-5

Marcuse H (1991) One-dimensional man: studies in the ideology of advanced industrial society, 2nd edn. Beacon Press, Boston

Mont O, Plepys A (2008) Sustainable consumption progress: should we be proud or alarmed? J Clean Prod 16(4):531-537

Polk M (2014) Achieving the promise of transdisciplinarity: a critical exploration of the relationship between transdisciplinary research and societal problem solving. Sustain Sci 9(4):439-451

Söderbaum P (2013) Ecological economics in relation to democracy, ideology and politics. Ecol Econ 95:221-225

Wamsler C et al (2018) Mindfulness in sustainability science, practice, and teaching. Sustain Sci 13(1):143-162

Publisher's Note Springer Nature remains neutral with regard to jurisdictional claims in published maps and institutional affiliations. 